\title{
The phenomenon study of effective communication of trainers in the induction training
}

\author{
Zahrah Nabila Azka ${ }^{1 *}$, Sikandar Hasib ${ }^{2}$ \\ ${ }^{1}$ Pasundan University Bandung, Bandung, Indonesia \\ ${ }^{2}$ Universitas Padjadjaran, Bandung, Indonesia
}

\section{Keywords \\ Effect \\ Communication \\ Trainers \\ Induction \\ Training \\ Motivation}

Received: 9 June 2020

Accepted: 28 October 2020

Published: 12 December 2020

\begin{abstract}
This research aims to determine the effective communication patterns of trainers in bank Mandiri employee induction training. The purpose of this study is to find out how the trainer interprets effective communication and find out the communication experience of the independent trainer identify the trainer's communication motives in providing induction training. Qualitative research methods using interpersonal competency theory were used. Research shows that trainers define training to develop insight, effective communication, and building cooperation. Education and training aim to be an inspiration, improve skills, provide knowledge, and change attitudes and worship. The benefits of training are applying company values, building networks, increasing competence. The key to the trainer's success is the success of the process, positive feedback from the participants, and the final success. Trainers also interpret training as a means to improve skills. This study uses a constructivist paradigm, where the researcher constructs the trainer's training communication experience. Activity trainer observed in this study are: motif coach, meaning coach, the communication experience coach and purpose of this research is the subject of study in the world of training at the same time the public, provides a basic overview of the topic, to generalize the idea and developed the theory of tentative, opening the possibility further research on the topics covered, and determine which techniques and directions will be used in future research.
\end{abstract}

(C) 2020 The Author(s). Published by TAF Publishing

\section{INTRODUCTION}

Training communication is a process of communication that is important for trainers to provide training from the start of implementation to the end of the training activities. In training, communication skills are needed from a trainer, starting from conveying material and building a conducive relationship with training participants to overcome obstacles that occur when training is taking place.

Trainers or facilitators are critical factors in the development and education of a company's employees, both new or old employees in a company. Therefore, a trainer's skill in training communication is required for the success of ongoing training. A trainer's skill is one factor that determines it, one of which is seen from the communication experience trainers. It is exciting and unique for researchers to see, un- derstand, and analyze this study about the communication experience in Trainer's terms of its communication aspects. Researchers looked at several trainers senior internal where the trainer researchers observe who has a communication proficiency and good Interaction with the participants so that the uniqueness and charm that is owned by Trainer. In this research, the trainers internal of the National Savings Bank (Mandiri) who teach Induction materials, including banking material, future package products, building productive centers, operational activities, and code of ethics are being examined.

\section{Research Focus}

The problem that becomes the focus of research is how the Effective Communication Patterns of Trainers in the Train-

\footnotetext{
* corresponding author: Zahrah Nabila Azka

†email: zahrahnabilaazka01@gmail.com
} 
ing InductionTunas Usaha Rakyat Mandiri. This research will be conducted qualitatively by collecting authentic data, which becomes the basis of effective communication for trainers in training independent induction.

\section{Research Questions}

The formulation of the problem in this study is How the Effective Communication Patterns of Trainer Communication at Induction Training Bank Mandiri.

1. How do Trainers interpret effective communication at Training Bank Mandiri Induction?

2. How is the communication experience trainer is in providing training to Mandiri?

3. What are the motives for communicating with trainers Mandiri providing Bank Mandiri training?

4. What are the success factors for trainer communication success by trainers in delivering Bank Mandiri materials?

\section{Research Objectives}

1. To find out which trainers interpret effective communication at Training Bank Mandiri Induction.

2. To find out the communication experience of the Trainer Mandiri.

3. To find out the motive communicate Trainer in training Training Bank.

4. This is to determine the success factors of the Trainer's communication success in presenting the Induction Bank Mandiri material.

\section{Research Usefulness}

From the results of this study, it is hoped that the following benefits will be obtained:

\section{Theoretical benefits}

a. For the Communication Science study program, this research is expected to contribute to research development in the communication discipline, especially in group communication.

b. The results of this study are expected to add references and sources of information and documentation for further research in the development of communication science and become a handbook for people who have problems similar to the problems that the researchers raised in this study.

\section{Practical benefits}

1. This research is expected to know and get information or a description of the communication of the Trainer Mandirin, the Bank Mandiri Induction Training.

2. It is hoped that it can become a reference for the world of training in implementing good communication to provide training for employees.

\section{LITERATURE REVIEW}

\section{Interpersonal Theory Competence}

In this study, the Interpersonal Theory is used in Competency Competency, in which a trainer must have the ability to create good relationships with participants and create a conducive atmosphere during the training. In interpersonal competence, communication is carried out by understanding others and oneself from their perspective, beliefs, thoughts, and feelings (Kongmanus, 2016; Perlman \& Cozby, 1983). This theory's relevance is that a trainer in conducting training communication must understand himself and others to understand himself by measuring the Trainer's abilities both from their knowledge and skills in developing communication when providing training. In contrast, in context, understanding other people, a trainer before giving training must know who the participants are, the participants' background, and the participants' training objectives. Both of these are done by trainers so that communication is communicative and effective.

Communication competencies that must be possessed by trainers, namely the ability to achieve the communication goals carried out, consist of three components: knowledge, skills, and motivation. To achieve this Competency Competency, you must first understand the communication situation, yourself, and the skills needed to communicate effectively. Second, we have to make use of knowledge and use skills. Doing this requires practice and experience, accompanied by the right behavior. Third, it must motivate oneself to communicate competently, namely knowing what to do because it develops their skills.

Interpersonal competence is the ability to communicate effectively (Devito, 1986; Purba \& Martono, 2017). Effectiveness in interpersonal relationships is determined by communicating what you want to convey, creating the desired impression, or influencing other people as desired (Johnson, 1981). Effective communication causes at least five things: understanding, pleasure, influence on attitudes, better relationships, and actions (Buhrmester, Furman, Wittenberg, \& Reis, 1988).

Pace (Arslan, 2016) states that interpersonal communication is a communication process that takes place between two or more people, which is carried out face-to-face or remotely where the sender can convey messages directly and message recipients can receive and respond directly. Furthermore, Gitosudarmo and Mulyono (Suranto, 2016) also explained that interpersonal communication is communication in the form of facial gaze, a form of interaction from 
one individual to another, and can be done in two directions both verbally and nonverbally, and as a means of sharing information and information. feelings between individuals and individuals or between individuals with small groups. Based on the description above, it can be concluded that interpersonal communication skills are an individual's knowledge and skills in conveying, receiving, assessing, developing and maintaining information or messages carried out by two people or a group of individuals both verbally and nonverbally, resulting in a lead-baiting effect. back directly in the communication process in order to achieve goals and fulfillment of the task of adolescent development, as well as to gain identity at the stage of adolescence. Interpersonal communication skills aim to meet the needs in order to achieve good and effective social relationships between individuals and their environment.

Knowledge of appropriate and inappropriate contexts of speech in interpersonal interactions and knowledge of the rules of nonverbal behavior, for example, limits on physical closeness to others and volume of voice, are part of interpersonal competence (Devito, 1986). Buhrmester et al. (1988) revealed that interpersonal competence includes the ability to take the initiative, the ability to be open, the ability to be assertive, the ability to provide emotional support, and the ability to manage conflicts that arise in interpersonal relationships.

Many individuals get interpersonal competence through the learning process, observing others, through clear instructions or instructions through trial and error, and so on. Better interpersonal competence will be obtained if the individual adds and improves his knowledge of interpersonal communication. This better interpersonal competence will cause these individuals to get more choices in interacting so that it is likely to produce effective interpersonal relationships (Devito, 1986).

\section{METHODOLOGY}

Participants participating in this training are the company's provisions to know the introduction of a Mandiri company. This training lasts for 4 (four) days. Organizing a large number of training in each city every week, of course, requires more attention. New employees recruited are at least junior high school who do not have work experience and master the banking world. Mandiri management has high hopes for the implementation of the training.

Implementation of the training conducted by the Department of Learning and Talent Management under the Division of Human Capital Management Corporate Bank. Learning and Talent Management has a mission to develop HR competencies to support the implementation of a business with superior performance. The Department is Learning and Talent Management currently facing major challenges in training at Bank Mandiri. A variety of learning strategies for training effectiveness are often tested in these regular training classes.

Training regularly held are training Basic, which is given to new employees and will occupy aposition. frontliner Therefore, cognitive strategies are needed that can help them improve their understanding.

In connection with this, researchers, through the research approach method with interpersonal Competence will interview several trainers independent as research informants related to researchers who want to know more about the experience and meaning of trainers in providing training or training as communicators and providing inspiration for training or training participants.

\section{RESULTS AND DISCUSSION}

\section{Symbolic Interaction Theory Symbolic}

Interaction is an approach built based on social formations of symbols, general meanings or meanings shared, and their use in communication both within self and orientation selftowards people. Others, in various interactions among social agents or actors. Symbolic Interaction seeks to understand human behavior from the human subject. Human behavior must be seen as a formed and regulated process by considering the expectations of others who are their interaction partners (Mulyana, 2006).

Symbolic interactions are related to relationships between individuals. According to Moleong (2007) there are five main points of symbolic Interaction looking at humans, namely:

1. Humans must be understood as social beings who carry out social interactions continuously throughout their life.

2. Humans are understood as thinking humans who interact with themselves.

3. Humans do not necessarily interpret their environment, but give meaning to their environment according to their interactions and thoughts.

4. Human behavior results from a current situation determined by that time, not because of past experiences.

5. Humans are described as figures who are active in relation to their environment.

Moleong (2007) argues the importance of using symbols when researchers use symbolic interaction theory. Symbols are social objects in interactions used as representatives and communication determined by them to give meaning, create, and change objects. 
Moleong (2007) defines Interaction as collective social action; individuals communicate with each other about what they are doing by orienting their activities to themselves. In the definition of Charon above, in this research, there are three essences: the keywords, namely, the first is Interaction, the second is communication, the third is the orientation of one's activities. Its relevance in training communication and communication experience is Trainer as follows: First, there is an interaction between trainers and trainees from the start of training to the end of the training, even after the training takes place.

The second communication created during the Interaction between trainers and participants is effective communication that positively impacts both the Trainer and the participants. The three activity orientations are reflected in the respective objectives set by the trainer and training participants.

It descriptions explanation of the theory of iteration symbolic above are used by researchers in this study that the researchers observe, see and reveal the symbols, the meanings of every day or meanings commonly understood between the trainers and trainees, and their use in communication both within ourselves self as well as in orientation self- towards other people. It means that the role of the Trainer in training communication must be more sensitive in capturing symbols and meanings that are obtained directly from training participants, both through verbal and nonverbal communication.

\section{Effective Communication Effective}

Communication is a communication made by a person to another where the response or effect on the communicant (both cognitive effects, affective effects, or conation effects) is in accordance with the communicator's goals.

According to Stewart L. Tubb and Sylia Moss (Mulyana, 2007), effective communication includes:

\section{Understanding}

Communication is said to be effective when the recipient of the message (communicant) gets a careful understanding of the message's content conveyed by the communicator. The primary failure to communicate is caused by the communicant's lack of understanding in examining the message content referred to by communication.

\section{Enjoyment}

Communication creates intimacy, warmth, and fun. Communication will be useful if there is a sense of pleasure between communication actors, both during and after communication.

3. Influencing Attitudes
Communication will be useful if the message conveyed is received by the communicant, then the communicant does something. Persuasive communication will be useful in influencing attitudes.

\section{Good Social Relations}

Communication aims to foster good relationships in the form of warmth and intimacy.

\section{Action}

Communication will be effective when there is a common understanding of interpreting a message. Communication effectiveness is usually measured by real action. For example, understanding between teachers and students interprets lessons.

\section{Motives}

Motives in this research are for researchers to become the motives for becoming a trainer and the motives for communicating trainers. The motives for communicating trainers in training researchers look at the trainers' expectations, the trainers' goals, the trainers' attitudes, and how the trainers make training exciting, and how to make training participants more interested in following the trainers' training. The motive is the reason or impulse in man that causes him to do something, the desire, desire, and other driving forces that come from within him, to do something. They give purpose and direction to our behavior. Also, the activities that we do every day have motives.

According to Schutz in his book Kuswarno (2013), there are three motives: the cause motive that shows past orientation, agar motive which shows the present orientation, and motive to show future orientation. He called it because motive to show the motive phase in the past and motive to show the future's motive phase.

Research is related to trainers' training communication so that researchers will look at the motives Trainer's. Why did research informants want to make trainers their profession? Here in the research, the researcher will ask, namely, what causes the informant's encouragement to become trainers and the purpose of being a trainer. Furthermore, from being a trainer, in this research with interpersonal competence, the researcher also wants to know how the self-concept is Trainer.

\section{Role of Trainers}

The Implementation of training in implementing curricula takes place in a learning process, in which the Trainer develops specific roles. These various roles include:

1) Role as a teacher, the Trainer, has the role of conveying knowledge by presenting the necessary information in the 
form of concepts, facts, and other information that enriches the participants' knowledge by actively engaging them to find the knowledge need for themselves.

2) Role as class leader, the Trainer, acts as the overall class leader, group leader, and group member. Each Trainer needs to plan, implement, supervise, and evaluate during the learning process because of their role.

3) As a guide, the Trainer needs to provide assistance and assistance to participants experiencing difficulties or problems, especially in learning activities, which are expected to be more active for participants to guide themselves. The form of guidance is given to direct, motivate, help solve problems, and guide activities.

4) The role of a facilitator, the Trainer, plays the role of creating environmental conditions that actively learn participants. The facilities include providing tools, materials, a stimulating and challenging atmosphere, problem-giving, the Trainer's inviting attitude and personality, and so on. With the right classroom environment, the learning process will be useful.

5) As an active participant, the Trainer often carries out group discussions and group work to solve problems, for example, formulating problems, looking for data, and making conclusions, and conditions can lead to a never-ending debate. The Trainer can provide information, direct thinking, point out solutions, point out the resources needed, etc.

6) Role as an expeditor, the Trainer also carries out a role by searching, exploring, and providing the resources needed by the class or group of participants, both from printed sources, from the community, from other institutions or agencies, in order to support the learning activities of the participants.

7) The role of a learning planner, the Trainer, plays a role in planning learning plans. The training process's success is also determined by the training activities in the preparation of these plans. Thus, the learning process is always and in accordance with the development of institutional conditions. Because it is closely related to providing references to the Trainer in carrying out the learning process.

8) In the supervisor's role, the Trainer must continuously supervise the class so that the learning process is always focused, the obstacles faced by the participants can be immediately overcome, classroom discipline can be adequately fostered, and all activities continue in an orderly and prosperous manner.

9) As a motivator, the Trainer needs to motivate the participants to learn, both during the learning process and outside the classroom. Motivation is essential for participants so that their learning activities are more active, for exam- ple, following lectures, making assignments, reading training materials, carrying out field practices, and so on.

10) In the role of an evaluator, the Trainer is obliged to make an assessment, at the beginning of the training, during the learning process, and at the end of the training, by giving written tests, oral questions, and observations. This assessment is essential to help participants know their learning progress, difficulties, and problems encountered, assist them with guidance, and for educational administration.

11) Role as a counselor, counseling (extension) as in learning difficulties, personal and social difficulties in exceptional times.

12) The role of investigating attitudes and values, the value system that serves as a role model for life, and attitudes needs to be investigated, considering that all training participants will be utilized as personnel serving the community. This is because the participants' outlook on life, beliefs, beliefs, and life attitudes needs to be observed and fostered according to the demands of future employment (Hamalik, 2007).

Some of the success factors of an instructor in bringing an instructor are as follows:

1. Want to provide training

Conduct training with enthusiasm, pleasure. Thus enthusiasm and joy will spread to the participants.

\section{Understanding what is given}

The Trainer not only understands the material training but also knows more than what is required.

3. Understand how to provide training

Many techniques can be used in delivering training. Each has advantages and disadvantages; trainers must choose and know how to use them according to their needs.

4. Understanding how people learn

There are many obstacles to learning and many ways to overcome them that make the teaching process faster and more reliable. Trainers must know these things.

5. Have the right attitude or personality. A trainer good must be firm, fair, and friendly (firm, fair, friendly).

6. Good at communicating.

In order to see the problems that exist, the Trainer must be able to empathize, seeing from the other person's point of view.

\section{Flexible}

Trainers must be flexible enough to make changes when needed, either in program or approach, even at the last minute.

The program training or training as component information attempts to improve one's self-development regarding the materials that one receives during the training. In the per- 
spective of De Cenzo and Robbins (1996), training is developing employee skills to do work in progress and work in the future.

Factors that help succeed trainers in providing induction training are preparing training materials, tools that help support training, such as pointers, laptops, LCD projectors. Prepare for the best appearance like Tuesday and Thursday using batik, Wednesday and Friday using polite and neat work clothes. Trainers must be able to maintain the mood when teaching, it could be that when the trainer has personal problems it should not affect their teaching performance. Checking the class, the layout must be done before the trainer teaches.characteristics Audience must be considered from gender, education, position, etc.

The training agenda can help trainers to find out the message of the material to be delivered, because the agenda contains the time, the name of the material, the location of the training, the content of the material to be delivered. Trainers must constantly improve their skills, attitudes and knowledge so that participants can be facilitated properly. As well as increasing the hours of teaching flying to be more skilled, by practicing creativity and improvisation when teaching, so as not to become people who have the same capacity when teaching. Able to follow and direct communication with participants. Train vocals so that they are pleasant to hear when communicating and interspersed with fresh humor for fun training.

In order to achieve successful training, a trainer must have interpersonal competence which is an indispensable ability to build and maintain close interpersonal relationships, especially in this study between trainers and trainees. With the existence of interpersonal competence, a person can be skilled in establishing effective relationships with others in overcoming various problems that can occur in interpersonal relationships and in training is the ability to adapt to training participants.

The ability to provide emotional support is useful for optimizing interpersonal communication between two persons. According to Barker and Lemle in Buhremester, emotional support includes the ability to calm and give comfort to others when the person is in a state of stress or problems. In this case the participant is in a state of confusion in facing a problematic customer. This ability is born from empathy in a person. According to Kartono and Gulo's views, it is the ability to understand other people's feelings. This feeling will be accepted by others as a warm gesture, and it will provide an important basis for the growth of a helping attitude. People who have the ability to have high empathy will have a high desire to help. From the description above, it can be concluded that providing emotional support is the ability to express one's concern, patience and sympathy for others. This is very necessary when trainers interact with participants.

According to David (2006) Understanding the body language conveyed by someone, whether accompanied by speech or not. We will be able to know the thoughts, feelings, desires, hopes, goals, motivations and what is behind a person's body language activity. Trainers can hone their ability to understand body language with more hours of flying, meeting many participants.

In addition to the factors described above, theassertive ability is trainer's very much needed in delivering training material, when giving feedback to participants about their appearance during simulations or material practice, it is theability to trainer's provide input without offending the participants' feelings. According to Perlman and Cozby, being assertive is the ability and willingness of individuals to express feelings clearly and be able to defend their rights firmly, asking others to do something and refusing to do things that are not desired without hurting the feelings of others.

Factors that support the success of trainers in delivering training materials, trainers must have an open attitude, where this ability is very useful so that the introductions that are already taking place can develop into a more personal and deep relationship. Kartono and Gulo revealed that openness is a process that a person takes until he is recognized by others. As the view expressed by Sears, et al, which states that everyone must do activities to share feelings and familiar information with others. Meanwhile, in self-disclosure, according to Wrightsman and Daux, someone always discloses personal information about himself and gives attention to others, as a form of appreciation that will expand the opportunities for sharing. open up, convey personal information and respect for others.

Researchers in this study used the approach Interpersonal Competency. Where this approach helps researchers to find out the individual's awareness in this case is the trainer in the event and the communication experience trainer's in providing training by paying attention to the communication process and aspects of communication carried out by the trainer. The theoretical foundation as study material used by researchers includes interpersonal competency theory and symbolic interaction theory.

This study uses the theory of interpersonal competency as stated by Devito (1986), which states that interpersonal competence is the ability to communicate actively, which means that a trainer cannot be separated from the commu- 
nication aspect of providing training. So that the communication aspect that takes place and is created by a trainer will determine the success or failure of the communication and training that he provides. The communication competence of a trainer to achieve the objectives of the communication carried out consists of three components, namely the knowledge trainer's, theskills trainer's and themotivation trainer's.

Researchers in this study will use theory as a basis and study that will be used in the discussion of research results. The theory used in this research is symbolic interaction theory. This symbolic interaction theory is used by researchers in this study, namely researchers observe, see and reveal symbols, general meanings or meanings that are shared between trainers and trainees, and their use in communication both within. self and Orientation self- towards others. The role of the trainer in training communication must be more sensitive in capturing symbols and meanings that are obtained directly from the training participants through both verbal and nonverbal communication.

Symbolic interaction theory is used in this study where the researcher makes observations on the trainer while providing training. Where the trainers build a harmonious relationship with the trainees so that what is the goal of the training that is delivered works well. The trainers are also inseparable from paying attention to the communication aspects at the time the training is carried out, which is constructed in the training communication process and the training communication aspects carried out. In training, the competence of a trainer is very concerned, in this study it is used, namely as stated by Devito (1986), it is said that interpersonal competence is the ability to communicate actively, a trainer cannot be separated from the communication aspect of providing training.

So that the communication aspects that take place and are created by a trainer determine the success or failure of the communication and training provided. The communication competence of a trainer to achieve the objectives of the communication carried out consists of three components, namely the knowledge trainer's, theskills trainer's and the motivation trainer's.

The following will describe the researcher's thoughts above into a picture of the framework of thought below:

1. Meaning of training communication

2. Communication Experience Trainer

3. Motive of training communication

4. Success factors of communication training

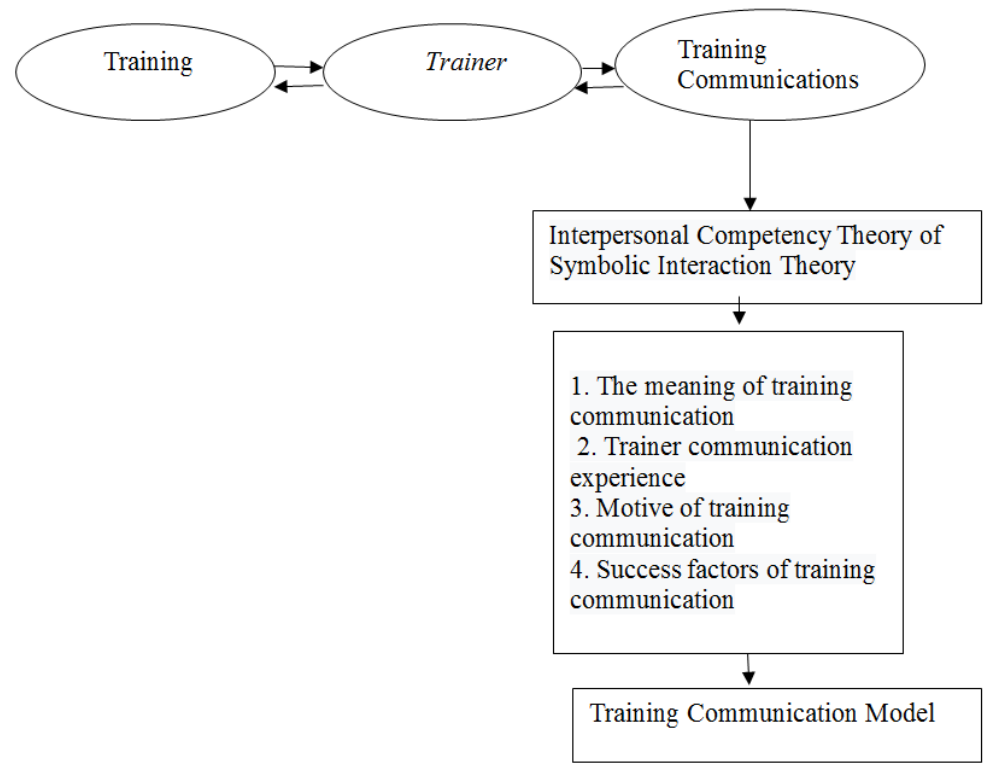

FIGURE 1. Theoratical framework

\section{CONCLUSION}

Based on the explanation of the results and discussion, several conclusions were obtained in this study.

1. Trainers interpret training to develop insights and skills, effective communication, and building cooperation. Trainers interpret training objectives as inspiration, self-skills trainers), provide knowledge, and change attitudes. As well as being worship to Allah SWT. In contrast, trainers' benefits are building networking, applying professional corporate values (PRISMA), integrity, mutual respect, and cooperation. In addition, trainers also interpret training communication as a means of increasing competence.

2. communication experiences Trainer in mastering the atmosphere training through engagement participant, part- 
ner sharing. Conducive training environment (room and facilities), creative thinking. Meanwhile, the communication experience in terms of the style used is interactive, attractive (interesting), visual, auditory, and kinesthetic and involves participants. The communication experience trainer attracts participants' attention by providing satisfaction, being friendly, ice breaking, displaying motivational words, and giving surprises such as rewards and stars for the most active participants. Experience of trainers in overcoming obstacles, namely mastering the material, expertise in the field of training.

3 . The motive for choosing a profession as a trainer is pointing to the past (because motive), which is like to speak in public, be active in organizations, have a sense of wanting to share. The communication motives trainer's refer more to the future (in-order-to-motive) which is reflected in expectations (useful for oneself and others and providing inspiration), goals (motivators and inspirators) and attitudes (learning partners, friendly and prejudiced good) ).

4. Factors that support the success of training communication by Trainer a well-prepared, initiative ability (knowing the characteristics of the participants, knowing the training environment, material and physical). Open ability, introduction, and sharing of experiences trainer, creativity (pacing-leading, vocals, intonation, and assertiveness), use of humor and the ability to provide support, personal approach (touching the heart, giving hope and assistance). As well as the ability to convey feelings without offending, namely being assertive.

\section{LIMITATIONS AND RECOMMENDATIONS}

This study is limited in scope as only the trainers from bank Mandiri were the focus of the study, which might affect the generalizability of the findings. However, further investigations in other banks and regions will give more reliable findings. Following implications are drawn from the study.

\section{Academic Suggestions}

1. Research with an objective approach will further provide a different picture in training communication research by trainers.

2. It is advisable for further research or similar research on training communication to study more broadly in addition to aspects of communication and communication processes.

3. Subsequent research not only in communication trainer but by looking at participants his training.

\section{Practical Suggestions}

1. It is recommended that trainers who make trainers as their profession must have a certificate in trainer accordance with the field or content they are mastered, it can be a certificate issued at the national or international level.

2. It is recommended that each company establish a learning/training center for the development of Human Resources for its employees.

3. It is better if thecommunity is socialized trainers club so that anyone who is interested in becoming a trainer can be trained, learn and get acertificate trainer.

\section{REFERENCES}

Arslan, C. (2016). Interpersonal problem solving, self-compassion and personality traits in university students. Educational Research and Reviews, 11(7), 474-481. doi:https://doi.org/10.5897/ERR2015.2605

Buhrmester, D., Furman, W., Wittenberg, M. T., \& Reis, H. T. (1988). Five domains of interpersonal competence in peer relationships. Journal of Personality and Social Psychology, 55(6), 991-1001.

David, O. S. (2006). Social psychology. Jakarta, Indonesia: Erlangga.

De Cenzo, D. A., \& Robbins, P. S. (1996). Human resource management. New York, NY: John Willey \& Sons.

Devito, J. A. (1986). Massage, building interpersonal communication skill. New York, NY: Harper \& Row.

Hamalik, O. (2007). Integrated approach employment training management. Jakarta, Indonesia: Earth Aksara Publisher.

Kongmanus, K. (2016). Development of project-based learning model to enhance educational media business ability for undergraduate students in educational technology and communications program. Journal of Advances in Humanities and Social Sciences, 2(5), 287-296. doi:https://doi.org/10.20474/jahss-2.5.5

Kuswarno, E. (2013). Phenomenology, conceptions, guidelines, and research examples. Bandung, Indonesia: Widya Padjadjaran.

Moleong, L. J. (2007). Qualitative research methodology. Bandung, Indonesia: PT. Youth Rosdakarya.

Mulyana, D. (2006). Qualitative research methodology: New paradigm of communication and other social sciences. Bandung, Indonesia: Cet V. PT. Youth Rosdakarya.

Mulyana, D. (2007). An introduction to communication science. Bandung, Indonesia: PT. Youth Rosdakarya.

Perlman, D., \& Cozby, P. C. (1983). Social psychology. New York, NY: Rinehart and Winston. 
Purba, C. S., \& Martono, D. (2017). Local act draft model on development, control, and telecommunication tower supervision. International Journal of Humanities, Arts and Social Sciences, 3(5), 231-240. doi:https://doi.org/10.20469/ijhss.3 .20006-5

Suranto, A. W. (2016). Komunikasi interpersonal. Yogyakarta, Indonesia: Graha Ilmu. 